\title{
Treatment of dystrophic calcification on a silicone intraocular lens with pars plana vitrectomy
}

\author{
This article was published in the following Dove Press journal: \\ Clinical Ophthalmology \\ 8 July 2014 \\ Number of times this article has been viewed
}

\author{
Nitish Mehta' \\ Roger A Goldberg ${ }^{2}$ \\ Chirag P Shah ${ }^{2}$ \\ 'University of Massachusetts \\ Medical School, Worcester, MA, USA; \\ ${ }^{2}$ Department of Retina, Ophthalmic \\ Consultants of Boston, Boston, \\ Massachusetts, USA
}

\begin{abstract}
Purpose: Dense, vision-obscuring calcification on the posterior aspect of silicone intraocular lenses (IOLs) is often not amenable to neodymium:yttrium-aluminum-garnet capsulotomy, and, in prior reports, has required IOL exchange. We report the successful removal of dense calcium deposition on the posterior surface of a three-piece silicone lens using pars plana vitrectomy (PPV).
\end{abstract}

Materials and methods: A 23-gauge PPV was performed using the Stellaris ${ }^{\circledR}$ vitrectomy system. A light pipe was used to retroilluminate the IOL, and a dense fibrous tissue setting with a low cut-rate and high aspiration rate was able to clear the visual axis of the dystrophic calcification without damaging the IOL optic.

Results: Visual acuity improved from 20/100 to 20/25.

Conclusion: Small-gauge PPV may be utilized to remove dense dystrophic calcium deposits on the lens surface in lieu of IOL exchange.

Keywords: cataract surgery, technique, Nd:YAG capsulotomy, IOL exchange

\section{Introduction}

Dystrophic calcification of the silicone intraocular lenses (IOLs) is a rare complication that can diminish visual acuity and contrast sensitivity. Dystrophic calcification has been reported with the use of silicone IOLs after vitreous hemorrhage or in patients with asteroid hyalosis, and it has been primarily treated with lens explantation, as neodymium:yttrium-aluminum-garnet (Nd:YAG) laser treatment often cannot remove dense deposits. ${ }^{1,2}$ The first report was published in 2004 by Wackernagel et al describing the composition of deposits on an explanted silicone lens 4 years after implantation. ${ }^{3}$ Recently, Mamalis et al reported the presence of calcium and phosphate in 16 explanted opacified silicone lenses from various manufacturers; $86.4 \%$ of those lenses were in patients with confirmed asteroid hyalosis. Concurrently, the authors analyzed 111 calcified hydrophilic acrylic lenses; none were associated with a history of asteroid hyalosis. ${ }^{4}$

Previous treatments of lens opacification have relied on the lens explantation alone with or without subsequent reimplantation of a new lens. ${ }^{1-4}$ This requires a large incision and risks refractive change. Herein, we describe a novel approach to treating patients with vision-obscuring dense calcification of silicone lenses without explantation of the IOL.

A 78-year-old woman underwent bilateral phacoemulsification and three-piece ClariFlex $^{\circledR}$ Silicone IOL insertion (Abbott Medical Optics Inc, Santa Ana, CA, USA). She had no significant past medical history and a past ocular history of asteroid hyalosis, greater in the right eye, and wet macular degeneration in the left eye with a central scar. Also, 9 years later, she described decreased vision in her right eye. Visual
Correspondence: Chirag P Shah

Department of Retina, Ophthalmic Consultants of Boston, 50 Staniford Street, Suite 600, Boston, MA 02114, USA $\mathrm{Tel}+\mathrm{I} 8006350489$

Fax +I 6177237028

Email cpshah@eyeboston.com 


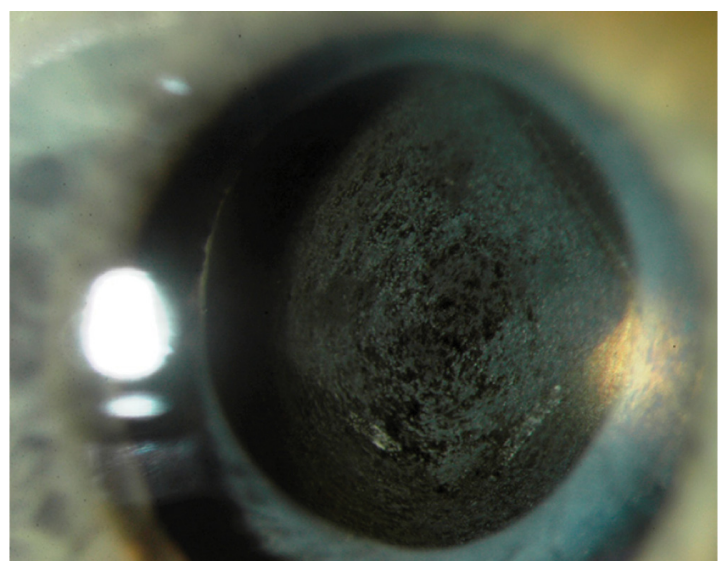

Figure I Slit-lamp photograph taken I month after the second attempted Nd:YAG capsulotomy shows granular deposits on the posterior optic surface that are not limited to the central IOL optic.

Note: Visual acuity was $20 / 100$

Abbreviations: Nd:YAG, neodymium:yttrium-aluminum-garnet; IOL, intraocular lens.

acuity was 20/100 in the right eye and count-fingers in the left eye. Examination revealed dystrophic calcification on the posterior surface of the right intraocular lens (Figure 1). At that time, a Nd:YAG capsulotomy was unable to clear the calcification. The patient's visual acuity remained unchanged. The procedure was reattempted 2 years later, again unsuccessfully.

\section{Technique}

To access the dystrophic calcification, a pars plana approach was taken using a Stellaris PC 23-gauge vitrectomy system (Bausch and Lomb Incorporated, Bridgewater, NJ, USA). After performing a core and anterior vitrectomy, the IOL was retroilluminated with the light pipe. A dense fibrous tissue setting was used with a high aspiration rate of 600 and a variable cut rate less than 1,500 cuts/minute to slowly remove the calcified material from the posterior aspect of the IOL, along with the posterior capsule. After clearing the central optic, the peripheral retina was carefully inspected. No retinal tears were identified, and the cannulas were removed. The patient received a standard postoperative regimen of antibiotic and steroid eye drops.

\section{Results}

The patient noticed immediate improvement in her vision. Her visual acuity was 20/25 without correction on postoperative day one, and the central optic was clear of dystrophic material (Figure 2). At 1 year, no material had reaccumulated on the central optic, and her vision remained stable at 20/25 (Figure 3).

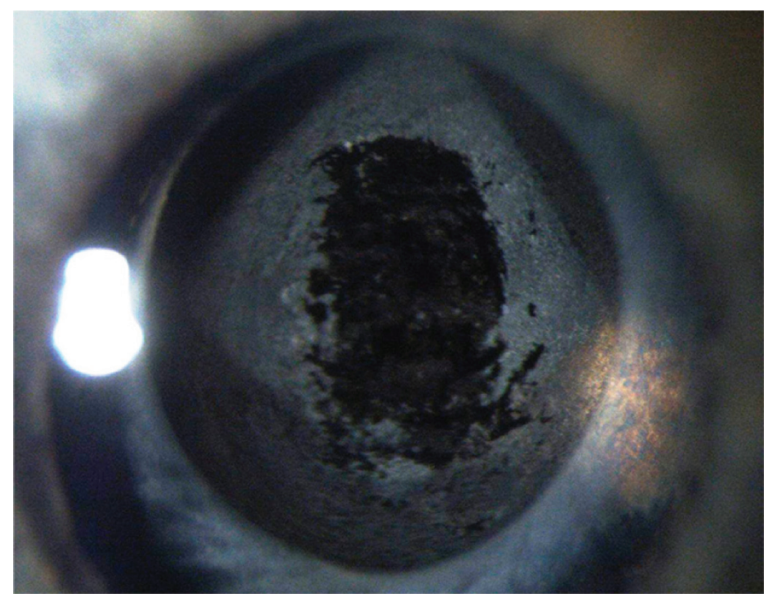

Figure 2 Slit-lamp photograph taken 3 weeks after PPV with posterior capsulotomy shows clearance of the granular deposits from the posterior optic surface in the visual axis.

Note: Visual acuity was 20/25.

Abbreviation: PPV, pars plana vitrectomy.

\section{Discussion}

Calcification of the posterior surface of silicone IOLs in patients with asteroid hyalosis is a rare but well-described late complication after cataract surgery. ${ }^{2}$ Prior reports in the treatment of this dystrophic calcification have required IOL explantation or exchange. A case series studying $22 \mathrm{IOL}$ exchanges identified complications in $36.4 \%$ of procedures, including corneal decompensation, loss of capsular support, vitreous prolapse, and an uncertain refractive outcome. ${ }^{5-7}$ In comparison, the United Kingdom National Ophthalmology Database Study of Vitreoretinal Surgery found only $7.8 \%$ of pars plana vitrectomies (PPV) had an intraoperative complication, the most common of which were iatrogenic retinal breaks $(3.2 \%){ }^{8}$

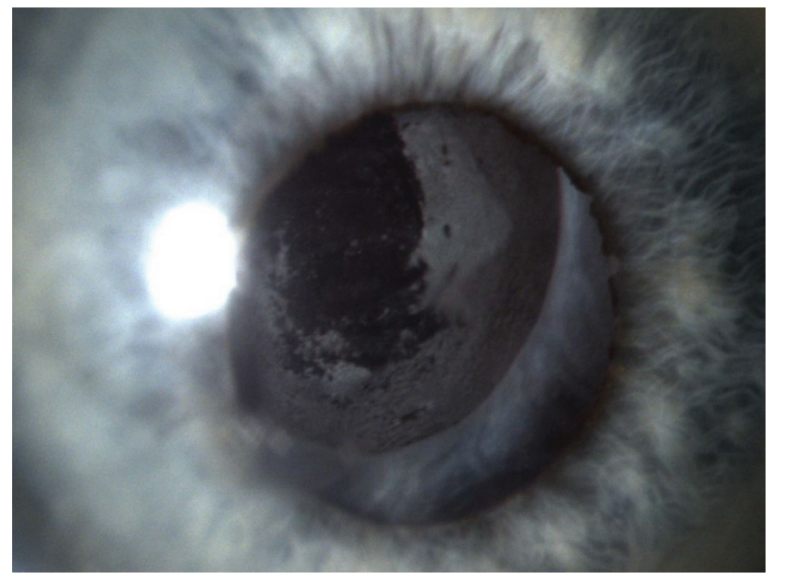

Figure 3 Slit-lamp photograph taken I year after PPV with posterior capsulotomy shows that the central optic remained free of dystrophic material.

Note: Vision remained at 20/25.

Abbreviation: PPV, pars plana vitrectomy. 
The use of a high-speed, small-gauge vitrectomy system to clear calcification with lasting results via a posterior approach allows use of the existing IOL with a more rapid surgical and visual recovery compared to IOL exchange. Patients maintain the same intraocular optics achieved immediately after cataract surgery and the chance of refractive alteration associated with IOL exchange is minimized. In theory, removing the asteroid bodies during vitrectomy decreases the risk of future calcium deposition on the silicone IOL optic. In the interest of saving a patient from the risks and refractive uncertainty of an IOL exchange, small-gauge PPV may be utilized to remove dense dystrophic calcium deposits from the lens surface.

\section{Acknowledgment}

The authors would like to acknowledge the Center for Eye Research and Education (CERE) of Boston, MA for their assistance in the publication of this manuscript.

\section{Disclosure}

The authors report no conflicts of interest in this work.

\section{References}

1. Werner L. Causes of intraocular lens opacification or discoloration. J Cataract Refract Surg. 2007;33(4):713-726.

2. Foot L, Werner L, Gills JP, et al. Surface calcification of silicone plate intraocular lenses in patients with asteroid hyalosis. Am J Ophthalmol. 2004;137(6):979-987.

3. Wackernagel W, Ettinger K, Weitgasser U, et al. Opacification of a silicone intraocular lens caused by calcium deposits on the optic. JCataract Refract Surg. 2004;30(2):517-520.

4. Mamalis N, Brubaker J, Davis D, Espandar L, Werner L. Complications of foldable intraocular lenses requiring explantation or secondary intervention - 2007 survey update. J Cataract Refract Surg. 2008;34(9): $1584-1591$.

5. Galor A, Gonzalez M, Goldman D, O'Brien TP. Intraocular lens exchange surgery in dissatisfied patients with refractive intraocular lenses. $J$ Cataract Refract Surg. 2009;35(10):1706-1710.

6. Chang JS, Ng JC, Lau SY. Visual outcomes and patient satisfaction after presbyopic lens exchange with a diffractive multifocal intraocular lens. $J$ Refract Surg. 2012;28(7):468-474.

7. Fernández-Buenaga R, Alió JL, Pinilla-Cortés L, Barraquer RI. Perioperative complications and clinical outcomes of intraocular lens exchange in patients with opacified lenses. Graefes Arch Clin Exp Ophthalmol. 2013;251(9):2141-2146.

8. Jackson TL, Donachie PH, Sparrow JM, Johnston RL. United Kingdom National Ophthalmology Database Study of Vitreoretinal Surgery: report 1; case mix, complications, and cataract. Eye (Lond). 2013;27(5) $644-651$
Clinical Ophthalmology

\section{Publish your work in this journal}

Clinical Ophthalmology is an international, peer-reviewed journal covering all subspecialties within ophthalmology. Key topics include: Optometry; Visual science; Pharmacology and drug therapy in eye diseases; Basic Sciences; Primary and Secondary eye care; Patient Safety and Quality of Care Improvements. This journal is indexed on

\section{Dovepress}

PubMed Central and CAS, and is the official journal of The Society of Clinical Ophthalmology (SCO). The manuscript management system is completely online and includes a very quick and fair peer-review system, which is all easy to use. Visit http://www.dovepress.com/ testimonials.php to read real quotes from published authors. 